\title{
REVISTA NOVA ESCOLA E AVALIAÇÃO EXTERNA: COMO OCORRE A CIRCULAÇÃO DE IDEIAS
}

\author{
LA REVISTA NOVA ESCOLA Y EVALUACIÓN EXTERNA: CÓMO \\ FUNCIONA LA CIRCULACIÓN DE IDEAS
}

\author{
REVISTA NOVA ESCOLA AND EXTERNAL EVALUATION: HOW THE \\ CIRCULATION OF IDEAS OCCUR
}

RESUMO: Este artigo tem por objetivo realizar o mapeamento e a análise das publicações regulares e especiais da revista Nova Escola que abordaram o assunto Avaliação Externa das Aprendizagens entre os anos de 2006 e 2015. Entende-se a importância de se verificar a forma como o tema é abordado, tendo em vista a grande representatividade da revista junto aos sujeitos escolares. É reconhecido pela literatura (Nóvoa, 2002), que jornais, revistas, boletins, cuja abordagem temática versa sobre educação, sejam eles elaborados pelo Estado ou por outras instituições, apresentam uma fonte rica de estudo, tendo em vista que através desses veículos de comunicação pode-se analisar concepções educacionais e prescrições de práticas de ensino. Assim sendo, a pesquisa buscou publicações e as classificou em quatro grupos: artigos específicos, matéria de capa, outras sessões e edições especiais. O mapeamento das publicações e sua análise contribuiu para a percepção da concepção que a revista apresenta sobre o sistema nacional de avaliação da educação básica, mais especificamente a Prova Brasil.

PALAVRAS-CHAVE: Avaliação Externa. Revista Nova Escola. Circulação de Ideias.

RESUMEN: En este artículo se pretende llevar a cabo el mapeo y análisis de las publicaciones periódicas y especiales de la revista Nova Escola que abordaron la cuestión de la evaluación externa de aprendizaje entre los años 2006 y 2015. Se entiende la importancia de verificar cómo el tema es abordado, en vista de la gran representación de la revista entre los sujetos escolares. Es reconocido por la literatura (Nóvoa, 2002), que periódicos, revistas, boletines, cuya temática enfoque la educación, sean elaborados por las instituciones del Estado o de otro tipo, tienen una rica fuente de estudio, pues a través de estos vehículos de comunicación se puede analizar los conceptos educacionales y prácticas de enseñanza. Por lo tanto, la investigación buscó publicaciones y las clasificó en cuatro grupos: artículos específicos, materias de tapa, otras sesiones y ediciones especiales. El mapeo de publicaciones y análisis contribuyó a la percepción de la concepción que la revista tiene del sistema nacional de evaluación de la educación básica, específicamente de la Prova Brasil.

PALABRAS CLAVE: Evaluación externa; Revista Nova Escola; la circulación de las ideas

${ }^{1}$ Doutoranda pelo Instituto de Educação da Universidade de Lisboa. E-mail: helenvoliveira@gmail.com

RIAEE - Revista Ibero-Americana de Estudos em Educação, v. 11, n. esp. 3, p.1645-1660, 2016.

E-ISSN: 1982-5587 
ABSTRACT: This article aims to carry out the mapping and the analysis of regular and special publications of the Nova Escola (New School) Magazine between the years 2006 and 2015, which addresses the theme of external evaluation of learning. The importance of verifying how this theme is addressed is understood, given the vast representation of the magazine amongst pedagogical participants. It is recognized by the literature (Nóvoa, 2002) that journals, magazines and bulletins that focus on themes related to education, whether they are developed by the state or other institutions, present a rich source of study, seeing as through these vessels of communication we can analyse educational concepts as well as explore prescribed teaching practices. Therefore, this research sought publications and classified them into four groups: specific articles, cover stories, other sessions and special editions. The mapping of publications and its analysis contributed to the perception of the ideals that the magazine presents about the national evaluation system of elementary education, specifically ProvaBrasil.

KEYWORDS: External evaluation. New School Magazine. Circulation of ideas.

\section{Introdução}

Este artigo tem por objetivo realizar o mapeamento e a análise das publicações regulares e especiais da revista Nova Escola que abordaram o assunto Avaliação Externa das Aprendizagens entre os anos de 2006 e 2015. Entende-se a importância de se verificar a forma como o tema é abordado, tendo em vista a grande representatividade da revista junto aos sujeitos escolares.

É reconhecido pela literatura (NÓVOA, 2002), que jornais, revistas, boletins, cuja abordagem temática versa sobre educação, sejam eles elaborados pelo Estado ou por outras instituições, apresentam uma fonte rica de estudo, tendo em vista que através de tais veículos de comunicação podemos analisar concepções educacionais e prescrições de práticas de ensino. No entanto, cabe ressaltar, como afirmam Rodrigues e Silva (2014), que tal fonte deve ser analisada levando em consideração sua produção, ou seja, quem a produz, e recepção, para quem é direcionada, tendo em vista a circulação de ideias pertinentes ao universo educacional.

De acordo com Nóvoa (2002), há três motivos que tornam importante o estudo dessas fontes e que, por conseguinte, acaba por impulsioná-lo. A primeira diz respeito à qualidade da imprensa para a apreensão no que tange a multiplicidade do campo educacional. O segundo motivo compreende a natureza da informação, visto que "apesar da diversidade da imprensa, pode afirmar-se que os escritos jornalísticos se definem pelo seu caráter fugaz e imediato, inscrevendo-se frequentemente numa lógica 
de reação a acontecimentos ou a ideias, as normas legais ou a situações políticas (p. 13). Por fim, o último motivo, em que destaca a imprensa como um lugar no qual ocorre afirmação em grupo e regulação coletiva.

A Nova Escola é uma revista que busca contribuir com a "melhoria do trabalho dos professores dentro da sala de aula". Apresenta conteúdos voltados para a Educação Infantil e o Ensino Fundamental, com tiragem mensal, com dez exemplares por ano, tendo em vista que a revista não é publicada em dois meses do ano, geralmente nos meses de férias escolares. Segundo dados da editora responsável, é a maior revista de educação do país, com 415.000 revistas impressas, 46.676 revistas digitais e 5.594 .000 acessos no site $^{2}$. A responsável pela Nova Escola é a Fundação Victor Civita, uma organização sem fins lucrativos que tem por objetivo "apoiar o trabalho de professores, gestores escolares e formuladores de políticas públicas da Educação Básica Brasileira". ${ }^{3}$

A revista foi lançada em 1986 com a parte editorial escrita por Victor Civita, destacando, na primeira edição, os objetivos da revista, que são "Fornecer à professora informações necessárias a um melhor desempenho de seu trabalho; valorizá-la; resgatar seu prestígio e liderança junto à comunidade; integrá-la ao processo de mudança que ora se verifica no país; e propiciar uma troca de experiências e conhecimentos entre todas as professoras brasileiras de $1^{\circ}$ grau", e sua parceria, desde então, com o Ministério da Educação, que propiciou que as então 220 mil escolas públicas de $1^{\circ}$ grau, atual Ensino Fundamental, recebessem a revista ${ }^{4}$. Esta política estabeleceu uma ampla circulação dos exemplares entre docentes e gestores escolares, o que até hoje continua por acontecer.

\section{Mapeamento do Tema Avaliação Externa na Revista Nova Escola}

A década de 1990 foi marcada, como tendência internacional, pela busca da melhoria e qualidade da educação, a avaliação "ganhava relevância como a política de Estado em todo o mundo" (Horta Neto, 2007, p. 8). O governo brasileiro busca a adequação a este movimento e exatamente no ano de 90 realiza a primeira prova do Sistema de Avaliação da Educação Básica - Saeb. Os objetivos propostos pelo primeiro ciclo tinham como base o desenvolvimento e/ou aprofundamento da capacidade das

\footnotetext{
${ }^{2}$ Disponível em: <http://publiabril.abril.com.br/marcas/nova-escola>. Acesso em: 17 jul. 2016.

3 Disponível em: <http://www.fvc.org.br/>. Acesso em: 17 jul. $2016 .$.

${ }^{4}$ Disponível em:<http://www.fvc.org.br/tablet/linhadotempo/1986-lancamento-novaescola.html?iframe=true \&width=790\&height=355> . Acesso em: 17 jul. 2016 .
} 
unidades gestoras do sistema educacional, o que proporcionaria regionalizar a operacionalização do processo avaliativo (INEP/PNUD, 1994, p. 7). Com isso, os governos subnacionais, por sua vez, também começaram a somar com avaliação próprias, seja no âmbito estadual ou municipal. Segundo o Centro de Políticas Públicas e Avaliação da Educação - CAEd (2015), dos 26 estados federados, 18 apresentam sistemas próprios de avaliação, ou seja, 69\%. Pode-se concluir que grande parte das unidades gestoras, no que tange ao nível estadual, apresentam sistemas próprios de avaliação.

O ano de 1990, por conseguinte, torna-se um marco inicial no que se refere ao sistema de avaliação em larga escala no Brasil. Outro marco na linha do tempo do sistema de avaliação da educação brasileira é a implantação da Prova Brasil em novembro de 2005. O que outrora vinham como dados que mais favoreciam ao sistema, ou seja, o Saeb como fonte de informação para gestores públicos, com ênfase nas políticas públicas de caráter amostral, a Prova Brasil passa a fornecer dados também a nível de unidade escolar com caráter censitário.

Levando em consideração a linha temporal da implantação do sistema de avaliação no Brasil, a pesquisa buscou publicações a partir do ano que sucedeu a aplicação do segundo marco, a Prova Brasil, sendo, por conseguinte realizado um mapeamento e análise do ano de 2006 até o ano de 2015. Os artigos foram classificados em quatro grupos: artigos específicos, matérias de capa, outras sessões e edições especiais sobre o tema. A busca ocorreu através do site, no qual realizou-se a análise do sumário dos 98 exemplares publicados neste período e mais 39 edições especiais. Através da busca nos sumários dos exemplares impressos disponibilizados no site, foi encontrado 22 publicações nas revistas regulares, 3 revistas com matéria de capa e 1 revista de edição especial. Não foi possível verificar os 100 exemplares, o que corresponderia ao total de revista do período analisado, pois o site, na data da elaboração deste texto, não havia disponibilizado as revistas de outubro e novembro de 2015. Cabe também ressaltar que quando o assunto é apresentado como matéria de capa, contém mais de uma publicação na mesma revista. Porém, para dados quantitativos, optou-se, nesta pesquisa, em pontuar apenas uma vez no número de publicações, entendendo que é uma matéria dividida em publicações menores.

Em um segundo momento, foi feito uma busca no site com as palavras Avaliação Externa, com o intuito de verificar se alguma publicação era apresentada e não havia aparecido no sumário. Essa busca gerou um resultado maior do que 
encontrado nos sumários. Tal fato ocorre devido a busca ser realiza não apenas nos conteúdos impressos da Revista Nova Escola, mas também nos conteúdos digitais da revista e também no conteúdo da revista Gestão Escolar, para além de pesquisas realizadas pela Fundação Victor Civita.

A revista Gestão Escolar faz parte da revista Nova Escola, porém com um foco maior na equipe de gestão escolar: diretores, coordenadores pedagógicos e orientadores educacionais. Teve início em 2010, com publicações bimestrais. De 39 revistas e 5 edições especiais, com uma busca simples com as mesmas palavras utilizadas para a Revista Nova Escola, gerou 17 referências sobre o tema mais uma edição especial. Observa-se, desse modo, que o tema também apresenta representatividade nessa revista. Porém não iremos contemplar a análise dela neste momento, nem dos conteúdos digitais e das pesquisas realizadas pela Fundação.

Em um mapeamento de 98 edições regulares e 39 edições especiais, pode-se constatar que em quase 10 anos de revista, o tema apareceu em todos os anos, foi contemplado em 3 capas, 36 publicações e 1 edição especial. Isso significa que o tema é considerado como importante para o editorial da revista. Tendo em vista que em uma comparação com outros temas da avaliação, pode-se perceber que a avaliação externa das aprendizagens foi a que recebeu maior destaque, aparecendo 37,9\% das publicações, ou seja, de 58 publicações sobre avaliação neste período, 22 delas dizem respeito as avaliações externas. Os demais assuntos abordados, por exemplo, foram: observação e registro na Educação Infantil, avaliação inicial, medo de prova, autoavaliação, correção de prova, qualidade na elaboração de prova, portfólio, apresentação oral.

Como capa de revista, ao todo foram 6 capas que abordaram o tema avalição, sendo $50 \%$ avaliação externa e as demais sobre avaliação diagnóstica, avaliação de qualidade e avaliação processual. Mais uma vez observa-se o destaque ao assunto, tendo em vista que metade das capas sobre avaliação apresentam como assunto a avaliação externa. No que toca às revistas especiais, das 39 edições ao longo deste período, uma revista aborda o tema avaliação, e o assunto é avaliação externa.

Em um levantamento realizado em todos os temas que foram capa da revista neste período, a avaliação externa fica atrás apenas da alfabetização e da educação sexual, que aparecem 5 e 4 vezes como matérias de capa respectivamente. Outros assuntos que também foram abordados três vezes foram leitura, educação ambiental, educação infantil, projetos e pré-escola. Como edição especial, os assuntos que mais receberam destaque foram educação infantil, pré-escola e projetos, todos com 3 edições. 
Com relação ao quantitativo por ano em que aparecem, observou-se que as matérias de capa foram publicadas nos anos seguintes à primeira aplicação da Prova Brasil - 2006, 2007 e 2009, sendo que os anos de 2007 e 2009 foram anos de aplicação da prova. As outras publicações estão espalhadas ao longo dos anos, não se observa diferenciação significativa de quantidade entre os anos de aplicação da avaliação com aqueles em que não ocorrem. Já a edição especial foi realizada no ano de 2011, também ano de avaliação. Considerando que a Prova Brasil ocorre a cada dois anos, houve publicação de duas capas e uma edição especial nos anos que ocorreram a aplicação do segundo ao quarto ciclo da prova.

Esse levantamento mostra que a avaliação externa das aprendizagens vem recebendo grande importância na revista Nova Escola. O que representa um reflexo no que se encontra no sistema educativo e nas políticas educacionais. Como afirmam Black e William (2001), sobre a realidade do Reino Unido, que, porém, não se difere neste ponto com relação ao Brasil, as atenções públicas e políticas e a maioria dos recursos disponíveis vem sendo concentrados nas avaliações externas, o que coloca no centro das atenções as avaliações somativas e delega a um status marginal as avaliações formativas.

Os testes aparecem como forte fator no que se refere a predominância de práticas internas somativas. Pacheco (2012) discorre sobre três pontos: políticas tendencialmente formativas, práticas predominantemente somativas e entre o desejo e o realizado. As políticas tendencialmente formativas são normativas apresentadas por meio de documentos oficiais, tais com parâmetros e diretrizes, com um movimento de contenção de avaliação somativa interna, na medida em que há uma sobrevalorização da avaliação formativa neste contexto. No entanto, apesar dos documentos oficiais possuírem um discurso de reconhecimento da avaliação formativa, percebe-se uma predominância de práticas somativas, vindo por isso a ter um discurso cujo objetivo é a avaliação formativa e a prática voltada mais para a somativa. Por fim, o autor refere-se à avaliação como um pêndulo que oscila entre a expectativa e o real, o ideal e o concreto, o referente e o referido.

Pode-se observar que para além dos sistemas de avaliações externas presentes no Brasil, que apresentam avaliações nacionais, estaduais e municipais; que devido ao número de avaliações presentes ao longo do ano, a atribuição de bonificação e premiação, de ranking das escolas reforçam as práticas somativas nos espaços escolares, existem outros meios nos quais as práticas somativas se apoiam. Os veículos de 
comunicação são um exemplo disso, principalmente aqueles que têm como principais leitores os professores e gestores educacionais. É perceptível na revista Nova Escola o destaque dado as avaliações externas, o que vem, por conseguinte, a sobrevalorizar as avaliações somativas em detrimento das avaliações formativas. A forma como a assunto é abordado na revista reforça também esta ideia.

\section{Análise das Publicações}

Depois de mapear todas as publicações presentes nas 99 revistas, 98 edições regulares e uma edição especial, buscou-se agrupá-las em quatro grupos: artigos específicos, matéria de capa, outras sessões e edições especiais sobre o tema.

\section{Artigos Específicos}

Foram considerados como artigos específicos os textos produzidos por especialistas da área de educação que escrevem sua opinião sobre um determinado ponto. Foram encontrados quatro artigos: setembro de 2015, novembro de 2011, novembro de 2009 e agosto de 2008. Dois artigos de autoria de Luiz Carlos de Menezes, docente da Universidade de São Paulo (USP), membro do Conselho Estadual de Educação de São Paulo, do Conselho Técnico Científico da CAPES/MEC para Educação Básica e consultor da UNESCO. João Luiz Horta Neto, escreveu um artigo, pesquisador do Instituto Nacional de Estudos e Pesquisas Educacionais (INEP), apresenta como campo de estudo as áreas de Avaliação de Sistemas, Instituições, Planos e Programas Educacionais. E Fernando José de Almeida, também com um artigo, professor da Pontifícia Católica de São Paulo, foi secretário de Educação da cidade de São Paulo e atualmente é Diretor de Currículo, Avaliação e Formação da Secretaria Municipal de Educação de São Paulo.

Cabe ressaltar que os três autores para além de acadêmicos, apresentam ligação direta com as políticas públicas, na medida em que possuem cargos de membro do Conselho Estadual de Educação; pesquisador do INEP, uma autarquia federal vinculada ao Ministério da Educação; e diretor da secretaria Municipal de Educação.

Luiz Carlos de Menezes, no texto Avaliações externas x melhoria da educação artigo específico, aborda o problema de os exames estarem ao invés de orientando a educação, estão por glorificar determinadas escolas e estigmatizar outras, competição associada a uma política pública empregada. Porém afirma que tal fato não deve levar a 
situações impensadas, como acabar com as avaliações. O texto então conclui de forma a refletir sobre como fazer melhor uso dos indicadores educacionais. $\mathrm{O}$ artigo Avaliação não é ameaça, o autor desenvolve a questão de exames terem a finalidade de orientação, uma forma de aferir a qualidade da Educação, não de "carimbar" uma instituição. Entende que as avaliações que são mais importantes são aquelas que orientam ao ensino, estão integradas ao processo de aprendizagem, criticando a prática de a avaliação ser a razão do trabalho educacional, no lugar de meio ou confirmação dele, devendo a avaliação ser vista como recurso, não como uma temida sentença.

Com o artigo Avaliação sem impacto na aprendizagem, Horta Neto busca realizar uma crítica ao sistema de accountability no Brasil, na qual afirma que a prática deve ser melhorada para verdadeiramente apresentar impacto na aprendizagem do aluno. O texto é construído a partir de um traçado histórico do sistema de avaliação, abordando assuntos como o interesse crescente por instrumentos de comparação de desempenho de estudantes em nível internacional, as políticas neoliberais e a época da accountability, a criação do Saeb e da Prova Brasil, a indução de sistemas próprios de avaliação a partir das avaliações do governo federal, a accountability no Brasil. O autor conclui reafirmando que a escola deve prestar contas do seu trabalho, por ser dever de qualquer instituição pública, no entanto destaca que outros fatores podem influenciar no desempenho dos alunos, como as diferenças socioeconômicas, e que a escola, juntamente com o Estado, deve conseguir superar estas dificuldades. Outro ponto de alerta do autor é o estreitamento do currículo, que vem ocorrendo devido ao fato de se buscar notas maiores ao invés de uma efetiva preocupação com o aprendizado, o que gera a preparação dos alunos para os testes.

Por fim, Fernando José de Almeida traz o texto intitulado Avaliação externa: vilã ou salvadora?, no qual trata da falta de envolvimento dos gestores escolares nos resultados do Idep - Índice de Desenvolvimento da Educação Básica. O autor destaque que em uma pesquisa realizada pela Fundação Victor Civita, apenas 2\% dos gestores atribuíram a si a responsabilidade pelo resultado no Idep. Destaca-se a importância do trabalho em conjunto dos diferentes atores educacionais, no entanto o gestor recebe um papel de destaque na responsabilidade, visto que, segundo Almeida, "Cabe a ele tomar a iniciativa de articular todos os interessados para, juntos, mobilizarem a comunidade 
para analisar o impacto das avaliações nas redes escolares. Sozinho, ele não é capaz de implantar a mudança, mas sem seu esforço pouco acontecerá.". 5

\section{Matéria de Capa}

Por três vezes a revista destacou a avaliação externa como matéria de capa: Em busca da qualidade na educação, Avaliação e Abrimos a caixa preta da Prova Brasil, respectivamente nas edições de outubro de 2006, janeiro/fevereiro de 2007 e maio de 2009.

Em busca da qualidade na educação teve publicação um ano após a aplicação da primeira Prova Brasil e quatro meses após a divulgação dos resultados. Uma das limitações desta pesquisa foi a análise do conteúdo desta reportagem, pois não se encontra disponível no site. Pela chamada da capa, observa-se que o conteúdo de qualidade da educação está estritamente ligado com a avaliação externa, tendo em vista que aparece como tópico da reportagem A escola número 1 no Prova Brasil. A relação entre qualidade da educação e avaliação externa é apresentada mais de uma vez na revista, vindo a receber destaque novamente na capa seguinte.

Em 2007, a revista traz a primeira edição do ano com o tema Avaliação. Neste ano, ocorreu a segunda aplicação da Prova Brasil, em novembro. A reportagem tem por objetivo a divulgação do resultado na primeira aplicação da Prova Brasil, a primeira prova ocorreu em 2005 e o resultado foi divulgado em 2006. Discorre como a Prova Brasil pode ajudar a melhorar a qualidade da educação, afirmando que "a divulgação dos resultados (desanimadores) da Prova Brasil reforça a ideia de que os testes são imprescindíveis para buscar a melhoria da qualidade da Educação.”6. A reportagem inicia expondo o "mal-estar" causado pela divulgação dos resultados no ano de 2006 e afirma que "é possível haver críticas aos testes criados pelo MEC", no entanto "muito mais importante é começar a construir, de uma vez por todas, uma cultura de que a avaliação é o caminho para sair desse buraco em que, todos concordamos, nossa Educação se encontra. "7. Em seguida, começa a explicar sobre o Sistema de Avaliação da Educação Básica, com foco na Prova Brasil, no qual apresenta o Boletim do Aluno

5 Disponível em: <http://novaescola.org.br/formacao/avaliacao-externa-vila-salvadora-gestao-escolardiretor-aprendizagem-gestor-responsabilidade-511320.shtml>. Acesso em: 02 ago. 2016.

${ }^{6}$ Disponível em: <http://novaescola.org.br/formacao/papel-avaliacao-424744.shtml>. Acesso em: 02 ago. 2016.

7 Disponível em: <http://novaescola.org.br/politicas-publicas/prova-brasil-detalhes-450869.shtml>. Acesso em: 02 ago. 2016. 
Brasileiro, isto é, como são apresentadas as notas da Prova Brasil e as competências consideradas em cada um dos níveis da escala. No final, a reportagem destaca seis escolas que tiveram as melhores médias na Prova Brasil na $4^{\mathrm{a}}$ série, atual $5^{\circ}$ ano.

Ao longo de doze páginas, a revista apresenta a estrutura da escola, o desempenho, qual fator contribuiu para o desempenho da escola e a fala de vários especialistas sobre o as considerações da escola, como: docentes da PUC-SP, diretora da Fundação Lemann, assessor de programa educativo na prefeitura de São Paulo, Exdiretor de Avaliação da Educação Básica do INEP e coordenadora pedagógica da Fundação Victor Civita. Os fatores levantados foram: a formação inicial e continuada do corpo docente, a força do trabalho de equipe, o papel do diretor, a participação da comunidade, a importância da leitura e o valor que a própria avaliação tem no dia-a-dia para melhorar a aprendizagem de todas as crianças.

A última capa foi no ano de 2009, em Abrimos a caixa preta da Prova Brasil, a revista realiza uma análise da prova de Língua Portuguesa da $4^{\mathrm{a}}$ série e apresenta orientações com a finalidade de auxiliar os professores com as habilidades que devem ser desenvolvidas, ou seja, como os descritores devem ser trabalhados em sala de aula. A edição, que ocorreu em maio, é considerada como um material para ajudar o docente no trabalho com os alunos para a Prova Brasil que ocorreu no mesmo ano em novembro, afirmando que "A amostra (de questões da prova de Língua Portuguesa) é representativa por esclarecer um ponto crucial: como as habilidades indicadas pelos descritores são avaliadas [...]. Para efetivamente ajudar você, mostramos como ensinar as habilidades que os alunos devem dominar." descritores de Língua Portuguesa, no entanto, no mês subsequente, a mesma análise ocorre com a disciplina de Matemática, em uma reportagem na qual aborda as habilidades que os alunos devem dominar e como devem desenvolvê-las, em A caixa preta da Prova Brasil de Matemática.

\section{Outras Sessões}

A avaliação externa aparece como tema de diversas sessões na revista, tais como: Em dia, Pesquisas, Entrevistas, Gestão Escolar, Educação em Debate, Nova Escola Discute.

${ }^{8}$ Disponível em: <http://novaescola.org.br/matematica/pratica-pedagogica/prova-brasil-espaco-forma475540.shtml>. Acesso em: 02 ago. 2016. 
Em dia foi a sessão que mais discutiu o assunto, com publicações como: as características de escolas com melhores e piores resultados; apresentação do site Devolutivas Pedagógicas, uma plataforma disponibilizada pelo Inep para auxiliar o professor e a gestão escolar com os resultados da Prova Brasil; anúncio da aplicação da prova do Pisa; anúncio de que a Prova Brasil será aplicada em escolas com mais de 20 alunos na zona rural. Parece um mural de avisos do próprio governo, com matérias que, em sua grande maioria, são anúncios sobre as avaliações externas.

Algumas entrevistas foram feitas também com estudiosos da área. Andreas Schleicher, responsável pelo Pisa, responde perguntas relacionadas ao Pisa e a qualidade da educação. Maria Alice Setubal, socióloga e presidente do conselho Fundação Tide Setubal, dentre outros assuntos, responde a perguntas relacionadas à bonificação por resultado e recursos para auxiliar escolas com piores resultados. E Cipriano Luckesi, professor da Universidade da Bahia, fala sobre a avaliação das aprendizagens, respondendo a perguntas sobre exames, vestibular, recuperação, currículo dentre outras.

Na sessão de Gestão Escolar, apresenta-se a matéria Selecionar quem participa das avaliações externas, que discorre sobre a questão da seleção de alunos para forjar condições mais favoráveis a elevação das notas das avaliações externas. Utiliza-se a fala de dois professores da Universidade de São Paulo, em que discorrem sobre a questão da pressão sobre as instituições provenientes de uma busca por melhores desempenhos e a questão da imposição ou sanção, uma dimensão da accountability, através de associação de resultados à premiação. No entanto, a reportagem segue com a apresentação de um trabalho desenvolvido por uma equipe gestora de uma escola em Rio Branco, na qual destaca-se os esforços em integrar todos na avaliação e utilizar os resultados para uma efetiva melhora da escola.

Uma pesquisa também é apresentada na qual afirma-se que não apenas as diferenças socioeconômicas são as "culpadas" pelos resultados distintos de estudantes da mesma escola nas avaliações externas, mas que fatores internos, de decisão da equipe gestores e de docentes, também interferem no desempenho. Tal afirmativa é levantada a partir de uma pesquisa realizada pela Fundação Victor Civitar e Instituto Itaú. A reportagem Combate à desigualdade passa então a apresentar alguns dados da pesquisa e conclui com a fala de uma professora da Universidade Federal do Paraná em que afirma que o professor deve identificar as desigualdades não para fazer um movimento de separação, mas sim para elaborar atividades específicas. 
Em Educação em Debate, a reportagem Ensinar melhor não é trabalhar somente o que cai na prova aborda a questão da preparação dos alunos para as avaliações em larga escala, destacando prática "pouco louváveis" por parte das escolas em diferentes regiões do país, mas para além disso, também toca no assunto da redução curricular por parte das secretarias de educação, com o intuito de melhorar o desempenho dos alunos, visto que privilegiam os conteúdos presentes nas avaliações externas. A reportagem conclui dizendo que o aumento na nota das provas não é sinônimo de qualidade, mas sim consequência, por isso não deve ser o foco das ações.

Idep, mais uma fábrica de rankings faz uma crítica ao sistema de ranking adotado pelo Idep, na sessão de Nova Escola Discute. O texto levanta algumas questões, tanto a nível do sistema, como metas pouco desafiadoras, falta de um currículo nacional; quanto por parte dos sujeitos escolares, como compreensão do índice, o que gera a uma falta de utilização efetiva para mudança, maquiagem por parte de escolas para melhorar o desempenho. $\mathrm{O}$ texto conclui afirmando a importância do Idep, mas ressalta que não tem sido, devido a forma como vem sendo divulgado e debatido, um instrumento que contribui diretamente para a melhoria da educação.

\section{Edição Especial}

Em agosto de 2011, a Nova Escola lança uma edição especial com o título Prova Brasil: Especialistas analisam 96 questões de Língua Portuguesa e Matemática para o $5^{\circ}$ e o $9^{\circ}$ ano. A edição foi lançada três meses antes da aplicação da prova. A finalidade da edição especial é ajudar os professores na preparação dos alunos para a prova, sendo dividida em quatro partes: Língua Portuguesa e Matemática para o $5^{\circ}$ ano; e Língua Portuguesa e Matemática para o $9^{\circ}$ ano. Em cada disciplina, há exemplos de questões de cada descritor, uma análise da questão e uma orientação para o professor desenvolver a habilidade. Como exemplo, analisaremos a forma como a Nova Escola abordou um tema de Matemática do $5^{\circ}$ ano e um tópico de Língua Portuguesa para o $9^{\circ}$ ano. A revista contemplou todos os temas de matemática e tópicos de Língua Portuguesa, porém não traz todos os descritores das matrizes de referências do Inep.

Para o $5^{\circ}$ ano, o tema Espaço e Forma é o primeiro, apresentando quatro descritores de cinco. $\mathrm{O}$ texto que abre o bloco informa:

Dentro desse descritor, as perguntas ficam mais complexas quando, além da identificação de expressões usadas no dia a dia, como "à direita" e "à esquerda" em 
exemplos simples, entram em cena outros elementos gráficos, como a malha quadriculada, presente num mapa [...]. Nesse caso, explica Edda Curi, a localização varia de acordo com a determinação de pontos de referência e o número deles depende da situação dada no enunciado. "Uma só informação não é suficiente para chegar à localização. É necessário identificar duas."9

Para o descritor 1, são apresentadas quatro questões com graus de dificuldade diferentes, no final delas é feita uma análise da última questão e termina com uma orientação para o trabalho desta habilidade

Os alunos vão aprimorar essas habilidades durante deslocamentos reais. Além disso, é útil apresentá-los a uma diversidade de circunstâncias que envolvam interpretar e descrever de forma oral e gráfica deslocamentos, trajetos e posições de objetos e pessoas por meio de desenhos e instruções orais ou escritas. Eles devem analisar pontos de vista, formas de representar, proporções, códigos e referências. O uso de mapas e croquis é essencial, pois eles demandam se colocar mentalmente na posição indicada. ${ }^{10}$

Assim ocorre com cada descritor do tema e no final há orientações didáticas que discorrem sobre explorar os diversos conhecimentos espaciais e explorar as figuras geométricas.

No que concerne à Língua Portuguesa, para o $9^{\circ}$ ano, o primeiro tema é Procedimentos de Leitura, contemplando todos os descritores. O texto que abre o bloco afirma

Esta prova exige repertório para ler e entender textos dos mais simples aos mais complexos, dependendo do vocabulário, da organização e das pistas linguísticas, entre outros aspectos. A análise das questões e as sugestões didáticas a seguir são de Claudio Bazzoni, assessor de Língua Portuguesa da Secretaria Municipal de Educação de São Paulo e selecionador do Prêmio Victor Civita - Educador Nota 10. ${ }^{11}$

Para o descritor 1 são contempladas três questões com gêneros textuais diferentes, no final apresenta-se uma análise das três questões e orientações para os professores.

Para trabalhar a habilidade relacionada a esse descritor, ler junto com os estudantes textos de diferentes gêneros e conversar muito sobre os sentidos deles é uma boa estratégia. Vale lembrar que compreensão e interpretação não são atividades que se realizam após a leitura, mas

\footnotetext{
${ }^{9}$ Disponível em:< http://novaescola.org.br/matematica/pratica-pedagogica/prova-brasil-espaco-forma475540.shtml>. Acesso em: 02 ago. 2016.

${ }^{10}$ Idem.

11 Disponível em: <http://novaescola.org.br/lingua-portuguesa/pratica-pedagogica/prova-brasil-9o-anoprocedimentos-leitura-510803.shtml>. Acesso em: 02 ago. 2016.
} 
durante ela. Em seguida, o ideal é recuperar com a turma as ideias principais e mostrar como elas formam blocos significativos no texto. ${ }^{12}$

\section{Conclusões}

As publicações da revista Nova Escola apresentam como foco, em sua maioria, a Prova Brasil. Entendendo que o Sistema de Avaliação da Educação Básica é dividido em três avaliações, a saber: Avaliação Nacional da Educação Básica (Aneb/Saeb), Avaliação Nacional do Rendimento Escolar (Anresc/Prova Brasil) e Avaliação Nacional da Alfabetização (ANA), acredita-se que a preferência pela maior abordagem da Prova Brasil dá-se pelo fato de ela ser de caráter censitário, já o Saeb é amostral; e a ANA avaliar apenas a alfabetização, além de apresentar dados a nível de unidade escolar.

Nos últimos dez anos, com relação à avaliação externa, pode-se observar que a matéria de capa esteve de maneira mais presente na revista Nova Escola nos anos que ocorreram as primeiras aplicações da Prova Brasil, como forma de familiarizar o professor com a nova avaliação. A capa de 2006 ocorre um ano após a primeira Prova, e aborda a questão da qualidade da Educação e o destaque da primeira escola no ranking; no ano de 2007 a matéria de capa então traz o resultado da primeira Prova Brasil, divulgado no ano anterior. Por fim, em 2009, a capa aborda a questão da "caixa-preta" da Prova Brasil, vindo por isso a desvendar os mistérios das questões, descritores e habilidades cobrados na prova, com a finalidade de auxiliar o professor em sala de aula na tarefa de preparar os alunos para o exame. As capas apresentam três movimentos que são presentes na Nova Escola, destacar a aferição da qualidade da Educação por meio das avaliações externas, sendo por conseguinte os testes "imprescindíveis para buscar a melhoria da qualidade da Educação"13; a busca por estabelecer uma cultura de avaliação para a melhoria da Educação; e ajudar os professores no desenvolvimento das habilidades nos alunos cobradas nos exames.

Apesar de apresentar críticas ao preparo dos alunos para os exames e a prática de ranking de escolas, com publicações do tipo Ensinar melhor não é trabalhar somente o que cai na prova e Idep mais uma fábrica de ranking, a revista expõe de forma muito

\footnotetext{
${ }^{12}$ Idem.
}

${ }^{13}$ Disponível em: <http://novaescola.org.br/formacao/papel-avaliacao-424744.shtml〉. Acesso em: 01 ago. 2016. 
marcada as características das escolas que estão nos primeiros e últimos lugares nos rankings e forma de se trabalhar com alunos os descritores da Prova Brasil, em publicações como Características das escolas com melhores e piores resultados e Abrimos a caixa-preta da Prova Brasil de Matemática. Este tipo de matéria, mais a ocorrência de publicações em anos de avaliação externa, pode ser um fator que juntamente com os testes reforçam as práticas somativas no cotidiano escolar, para além da redução do currículo e o trabalho para o resultado das avaliações externas.

A utilização da fala de especialistas da educação serve para dar autoridade ao discurso da revista, para que assim tenha maior credibilidade junto aos leitores. Em praticamente todas as publicações há a participação de mais de um professor universitário, para além de referência de outros autores. Pessoas com ligação aos órgãos governamentais, ou que já tiveram, também têm representatividade, como pesquisadores do Inep, membro do Conselho Estadual de Educação, diretor da secretaria Municipal de Educação, vindo a representar de forma direta o discurso do governo. Cabe ressaltar, para além disso, a entrevista com Andreas Schleicher, responsável pelo Pisa, avaliação internacional de maior peso na atualidade, no qual o Brasil participa desde o ano de 2000.

Por fim, o fato de a revista, desde a primeira edição, ter parceria com o Ministério da Educação, o que possibilita uma ampla divulgação nas escolas públicas no território nacional e a sua concepção estar estritamente vinculada a ideia governamental sobre o sistema de avaliação da educação básica. Apesar das críticas nos artigos específicos e em algumas outras publicações, constata-se uma forte ideia de estruturação da cultura de avaliação externa, esclarecimento para os docentes do funcionamento do sistema avaliativo e anúncios sobre os exames.

\section{REFERÊNCIAS}

BLACK, P.; WILIAM, D. Inside the black box: Raising Standards Through Classroom Assessment. London, 2001. Disponível em: <https://weaeducation.typepad.co.uk/files/blackbox-1.pdf>. Acesso em: 29 ago. 2016.

CAED. Sistemas Estaduais de Avaliação da Educação Básica: Abrangência dos atuais sistemas. Juiz de Fora, 2005. Disponível em: <http://www2.camara.leg.br/atividade-legislativa/comissoes/comissoespermanentes/ce/audiencias-publicas-1/apresentacoes/apresentacao-lina-katia-ufjf- 
sistemas-de-avaliacao-da-educacao-basica>. Acesso em: 20 jun. 2016.

INEP/PNUD. Sistema nacional de avaliação da educação básica: objetivos, diretrizes, produtos e resultados. Brasília, 1994. Disponível em: <http://www.dominiopublico.gov.br/download/texto/me002195.pdf>. Acesso em: 20 jun. 2016. Acesso em: 24 jun. 2016.

HORTA NETO, J. L. Um olhar retrospectivo sobre a avaliação externa no Brasil: das primeiras medições em educação até o SAEB de 2005. Revista Iberoamericana de Educación, 2007. Disponível em: <rieoei.org/deloslectores/1533Horta.pdf>. Acesso em: 20 jun. 2016.

NÓVOA, A.. A imprensa de educação e ensino: concepção e organização do repertório português. In: CATANI, D. B.; BASTOS, M. H. Educação em revista: a imprensa periódica e a história da educação. São Paulo: Escrituras Editora, 2002.

PACHECO, J. A.. Avaliação das Aprendizagens: Políticas formativas e práticas sumativas. 2012. Disponível em: <http://repositorium.sdum.uminho.pt/handle/1822/21170>. Acesso em: 30 abr. 2016.

RODRIGUES, E. S. Michele Juliana. A imprensa pedagógica representada pela Revista Brasileira de Educação: uma fonte de pesquisa para a história da educação. Florianópolis: $\quad$ X ANPED Sul, 2004. Disponível em: <http://xanpedsul.faed.udesc.br/arq_pdf/109-0.pdf>. Acesso em: 01 jul. 2016.

\section{Como referenciar este artigo}

OLIVEIRA, Helen Vieira de. Revista nova escola e avaliação externa: como ocorre a circulação de ideias. Revista Ibero-Americana de Estudos em Educação, Araraquara/SP, v. 11, n. esp. 3, p.1645-1660, 2016. Disponível em: <http://dx.doi.org/10.21723/riaee.v11.n.esp3.9079) . E-ISSN: 1982-5587.

Submetido em: agosto/2016

Aprovado em: novembro/2016 